\title{
Effects of Singing on Oral Function, Stress, and Immunity
}

\author{
Katsuhisa Sakano ${ }^{1,2}$, Koufuchi Ryo ${ }^{1}$, Yoh Tamaki ${ }^{3}$, Ryoko Nakayama ${ }^{1}$, Shukuko Ebihara ${ }^{4}$, Keisuke Tozuka ${ }^{5}$ and Ichiro Saito ${ }^{1 *}$ \\ ${ }^{1}$ Department of Pathology, Tsurumi University School of Dental Medicine 2-1-3, Tsurumi-Ku, Yokohama 230-8501, Japan \\ ${ }^{2}$ PREMEDiCO Co., Ltd., 4F Chushin Build. 3-3-5, Uchikanda Chiyoda-ku, Tokyo 101-0047, Japan \\ ${ }^{3}$ Department of Health and Welfare Services, National Institute of Public Health 2-3-6 Minami, Wako-shi, Saitama 351-0197, Japan \\ ${ }^{4}$ Chiyoda Paramedical Care Clinic, 2F Chushin Build. 3-3-5, Uchikanda Chiyoda-ku, Tokyo 101-0047, Japan \\ ${ }^{5}$ Daiichikosho Co., Ltd. 5-5-26 Kitashinagawa, Shinagawa-ku, Tokyo 141-8701, Japan
}

\begin{abstract}
Background: We previously reported that singing can improve mental health and oral function. Since the results were based on one singing session, further investigation was required. Therefore, we assessed the effects of daily singing on oral and immune/endocrine function in two studies.

Methods: Thirteen subjects (five men, eight women) with a mean age of 51.3 years (standard deviation [SD] = 13.0) and 17 subjects (six men, 11 women) with a mean age of 46.8 years $(\mathrm{SD}=8.0)$ participated in study 1 and study 2 , respectively. The effects of singing on oral function, immunity, and stress were determined by performing a swallowing function test, oral cavity examination, blood and saliva tests, and questionnaires before and after the singing period.

Results: Both chewing and swallowing showed significant improvement with singing (study 1), and saliva production also improved significantly with singing (study 2). In study 1 , immunological analysis showed a significant increase of T cells, B cells, CD4+ T cells, and CD8+ T cells with singing, and immunity scores increased significantly from week 4 through week 8 compared to before singing. The mood and emotional state of the participants (visual analog scale) improved in both studies, along with reduction of cortisol and adrenaline, which are indicators of psychological stress. Levels of lipid peroxide and 8-hydroxy-2'-deoxyguanosine, markers of oxidative stress, were also reduced in both studies.
\end{abstract}

Conclusions: Singing effectively promotes oral function, including saliva secretion and muscle strength, and reduces psychological stress. Singing may also improve immune function and reduce oxidative stress.

\section{Introduction}

Oral function strongly influences health and quality of life. Feeding relies on oral function, while speech and facial expressions are crucial for communication [1]. Swallowing is linked to complex higher brain functions, and eating is associated with learning and memory $[2,3]$. Saliva cleans the oral cavity and reduces micobial proliferation [4-6]. Saliva contains various molecules involved in immunity and health maintenance [7- 11], but their secretion decreases with aging [12,13]. Impaired chewing and swallowing are associated with aspiration pneumonia. Among the elderly, pneumonia is a frequently fatal and complications such as diffuse aspiration bronchiolitis can further increase mortality [14]. Hence, the oral cavity is important for both health and quality of life.

Reducing psychological stress may prolong the lifespan [15], while stress caused by isolation increases mortality [16]. Stress also negatively impacts immune function. Accordingly, stress reduction methods have been investigated [17-19].

Increased oral muscle strength is associated with greater secretion of saliva [20], and exercising the mimetic muscles can affect emotions [21]. We previously showed that saliva secretion increases after singing a single song and the participants reported emotional improvement [22]. This time, we investigated the effects of daily singing on oral function and health.

\section{Methods}

\section{Study design}

An open-label study (study 1) and a randomized, single-blind, cross-over study (study 2) were conducted after receiving approval from the Institutional Review Board of Chiyoda Paramedical Care Clinic (Tokyo, Japan). In accordance with the Declaration of Helsinki, the contents and methods of the study and other pertinent information were adequately explained to the participants, who provided written consent. Both studies were approved by the Institutional Review Board of Chiyoda Paramedical Care Clinic (approval numbers: study 1:13011702; study 2:14102102). Both studies were performed according to the Declaration of Helsinki and the subjects gave informed consent to participation.

\section{Participants}

Subjects were recruited by using a website. Study 1 was conducted in 13 subjects (five men and eight women with a mean age of 51.3 years; standard deviation $[\mathrm{SD}]=13.0$ years) and study 2 enrolled 17 subjects (six men and 11 women with a mean age of 46.8 years; SD $=8.0$ years). All subjects satisfied the selection criteria and provided written consent to participation. Exclusion criteria were current treatment for respiratory, cardiac, or vascular conditions; regular intake of health foods that could modulate stress or immunity and have an impact on study outcomes; a history of serious heart, lung, kidney, gastrointestinal (including gastrectomy), hematological, endocrine,

Correspondence to: Ichiro Saito, DDS, PhD, Department of Pathology, Tsurumi University School of Dental Medicine, 2-1-3, Tsurumi-Ku, Yokohama, 230-8501 Japan, E-mail: saito-i@tsurumi-u.ac.jp

Key words: singing, immune system, oral function, psychological stress

Received: January 04, 2018; Accepted: January 20, 2018; Published: January 24, 2018 
or metabolic disease or current treatment for any of these diseases; difficulty attending $\mathrm{t}$ hospital; depression, psychological instability, or strong psychogenic reaction; and any other reason that made the subject unsuitable according to the responsible physician. A profile of the participants is shown in Table 1.

\section{Study schedule and procedures}

Study 1 was an open investigation. Subjects were assessed at three baseline visits before the singing period, as well as after four and eight weeks of the singing period. Study 2 was performed according to a cross-over design. Subjects were assessed at four baseline visits before intervention, and then after four weeks of singing or not singing. They subsequently switched to the other intervention and were assessed again after a further 4 weeks. During the singing period of both studies, the subjects sang karaoke four times a week for one hour each time (five songs or more). The frequency of singing was set within the range that would not interfere with daily life. Singing in a karaoke box was selected because it is popular in Japan. Subjects sang alone in the karaoke box and they selected the songs themselves. The subjects were instructed to live normally, but to avoid drinking and eating excessively on the day before and the day of each examination, since overindulgence or poor health (e.g., fever or abdominal pain) could influence secretion of saliva. From 9 p.m. on the day preceding each visit, subjects were prohibited from the following activities until after completing the visit: drinking alcohol, consuming food/drink that could influence stress markers in saliva (green tea, coffee, soda, and high-caffeine beverages such as energy drinks), excessive exercise (physical stress can potentially affect salivary stress markers), and use of antihistamines (which inhibit secretion of saliva). On the examination day, subjects were prohibited from smoking until after completion of the examination. Subjects arrived at Chiyoda Paramedical Clinic in the morning and were interviewed by the study doctor. Then the body weight, blood pressure, and pulse rate were measured. Subsequently, examinations were performed in the following order: resting test, Saxon test, gum test, repetitive saliva swallowing test (RSST), measurement of bite force, questionnaire, and collection blood and urine samples.

\section{Measurements}

Blood levels of lipid peroxides, cortisol, and catecholamines (adrenaline and noradrenaline) were analyzed. The immunity score, comprised of the immunity grade and T lymphocyte age, was calculated by the Scoring of Immunological Vigor (SIV) method [23, 24]. All measurements and calculations of immunological markers were performed by the Institute of Health and Life Science (Tokyo, Japan). Urine samples were analyzed to measure 8-hydroxy-2'deoxyguanosine (8-OHdG). Secretion of saliva was assessed by the resting test, Saxon test, and gum test. Oral function and swallowing were examined by the RSST and bite force measurement. To complete the questionnaire, participants selected answers on a visual analog scale (VAS). In addition, the height, weight, blood pressure, and pulse rate were measured.

\section{Statistical analysis}

Results are expressed as the mean $\pm \mathrm{SD}$, unless otherwise specified. The Wilcoxon signed-rank test was used to compare data obtained at each visit with the baseline values. All analyses were performed with significance set at $\mathrm{p}<0.05$ (two-tailed) using SPSS 20.0 software (IBM Japan Inc., Tokyo, Japan) and SAS 9.2 software (SAS Institute Inc., North Carolina). In study 2 , data obtained by the $2 \times 2$ crossover design were analyzed by using PROC GLM in the SAS program.

\section{Results}

\section{Compliance with singing therapy}

A $100 \%$ compliance rate was defined as singing on 32 days (study 1) or 16 days (study 2) for one hour per day, with five or more songs in each singing session. Table 2 shows compliance with singing therapy. The compliance rate was $101.7 \pm 4.3 \%$ in study 1 because two subjects sang on 33 days and one subject sang on 37 days, while the remaining subjects sang on 32 days as scheduled.

\section{Saliva secretion and oral function}

The data on oral function and saliva secretion obtained in study 1 are listed in Table 3. Compared to baseline, the RSST value increased

Table 1. Profile of the participants.

\begin{tabular}{|c|c|c|c|c|c|c|}
\hline & \multicolumn{3}{|c|}{ Study 1} & \multicolumn{3}{|c|}{ Study 2} \\
\hline No. & \multicolumn{3}{|c|}{13} & \multicolumn{3}{|c|}{17} \\
\hline Sex (Male/Female) & 5 & I & 8 & 6 & I & 11 \\
\hline Age (years) & 51.3 & \pm & 13 & 46.8 & \pm & 8 \\
\hline Height $(\mathrm{cm})$ & 161.06 & \pm & 7.86 & 160.7 & \pm & 7 \\
\hline Weight $(\mathrm{kg})$ & 61.21 & \pm & 15.57 & 63.28 & \pm & 16.56 \\
\hline $\mathrm{BMI}\left(\mathrm{kg} / \mathrm{m}^{2}\right)$ & 23.552 & \pm & 5.691 & 24.331 & \pm & 5.442 \\
\hline $\mathrm{SBP}(\mathrm{mmHg})$ & 115.7 & \pm & 17 & 115.9 & \pm & 14.9 \\
\hline $\mathrm{DBP}(\mathrm{mmHg})$ & 73.8 & \pm & 12.9 & 73.4 & \pm & 11.6 \\
\hline Pulse rate (bpm) & 76.5 & \pm & 5.4 & 76.2 & \pm & 8.0 \\
\hline
\end{tabular}

Data are shown as the mean \pm SD

BMI, body mass index; bpm, beats per minute; DBP, diastolic blood pressure; SBP, systolic blood pressure; SD, standard deviation

Table 2. Compliance with Singing Therapy.

\begin{tabular}{|c|c|c|c|c|c|c|}
\hline & \multicolumn{3}{|c|}{ Study 1} & \multicolumn{3}{|c|}{ Study 2} \\
\hline No. of days performed & 32.5 & \pm & 1.4 & 15.9 & \pm & 0.2 \\
\hline Compliance rate (\%)* & 101.7 & \pm & 4.3 & 99.6 & \pm & 1.5 \\
\hline No. of songs per session & 10.1 & \pm & 2.5 & 7.8 & \pm & 1.4 \\
\hline
\end{tabular}

Data are shown as the mean $\pm \mathrm{SD}(\mathrm{n}=13)$

$* 100 \%$ compliance rate $=$ singing on 4 days per week during the study period.

$\mathrm{SD}$, standard deviation 
Table 3. Swallowing and oral function in study 1.

\begin{tabular}{|c|c|c|c|c|c|c|c|c|c|c|}
\hline \multirow[b]{2}{*}{ RSST } & \multirow[b]{2}{*}{ (times) } & \multicolumn{3}{|c|}{ Baseline } & \multicolumn{3}{|c|}{ week 4} & \multicolumn{3}{|c|}{ week 8} \\
\hline & & 4.5 & \pm & 1.4 & 5.4 & \pm & $1.3^{*}$ & 5.8 & \pm & $1.5^{* *}$ \\
\hline Bite force test & $(\mathrm{kN})$ & 0.087 & \pm & 0.082 & 0.088 & \pm & 0.04 & 0.101 & \pm & $0.043^{*}$ \\
\hline $\begin{array}{l}\text { Unstimulated } \\
\text { saliva test }\end{array}$ & $(\mathrm{mL})$ & 3.1 & \pm & 3.1 & 3.3 & \pm & 2.9 & 3.1 & \pm & 2.4 \\
\hline Saxon test & (g) & 4 & \pm & 1.9 & 4.8 & \pm & 1.6 & 4.8 & \pm & 2 \\
\hline gum test & $(\mathrm{mL})$ & 15.7 & \pm & 8.6 & 18.1 & \pm & 6.1 & 17.6 & \pm & 5.6 \\
\hline
\end{tabular}

Data are shown as the mean \pm SD $(n=13)$.

${ }^{*} \mathrm{p}<0.05, * * \mathrm{p}<0.01$ : Wilcoxon signed-rank test vs. Baseline.

RSST, repetitive saliva swallowing test; SD, standard deviation

significantly during the singing period. Before singing therapy, RSST was $4.5 \pm 1.4$ per session. After four weeks of singing therapy, RSST increased to $5.4 \pm 1.3$ per session and it increased further to $5.8 \pm 1.5$ per session after 8 weeks. In addition, bite force increased significantly from $0.087 \pm 0.082$ kilonewtons $(\mathrm{kN})$ at baseline to $0.101 \pm 0.043 \mathrm{kN}$ in week 8 of the singing period ( $\mathrm{p}=0.028$ ). The gum test and Saxon test values were also increased in both week 4 and week 8 compared with baseline, but the changes were not significant.

Data on oral function and saliva secretion obtained in study 2 are displayed in Table 4. According to the unstimulated saliva test, production of saliva was significantly greater in the singing group compared to the non-singing group during the singing period $(\mathrm{p}=0.013)$. In week 4 , the RSST, gum test, and Saxon test values were also higher in the singing group compared with the non-singing group, but these differences were not significant.

\section{Immune function}

Table 5 lists the results of the immunological tests performed in study 1 . The immunity score was significantly increased in week 4 and week 8 compared with baseline, while the immunity grade was significantly increased in week 4 of the singing period. Both CD3+ $\mathrm{T}$ cells and $\mathrm{CD} 8+/ \mathrm{CD} 28+\mathrm{T}$ cells also showed a significant increase in week 8 , while CD20+ B cells and naïve $\mathrm{T}$ cells were significantly increased in week 4 . In weeks 4 and 8 , the number of CD4+ naïve T cells and the naive $\mathrm{T}$ cell/ memory $\mathrm{T}$ cell ratio showed a significant increase. Finally, the CD4+ memory $\mathrm{T}$ cell count was significantly decreased in weeks 4 and 8 , while CD56-/16+ NK cells were significantly decreased in week 8 .

\section{Hormones and oxidative parameters}

Table 6 shows the results for study 1. Compared with baseline, the blood level of lipid peroxide was significantly decreased in week 4 of the singing period. In addition, blood levels of cortisol and adrenaline were significantly decreased in week 8 . While the urine level of 8-OHdG was decreased in weeks 4 and 8 , the change was not significant.

The results for study 2 are shown in Table 7. Compared with the non-singing group, urine $8-\mathrm{OHdG}$ in was decreased at 4 week in the singing group, but the change was not significant.

\section{Questionnaire}

Results of the questionnaire are shown in Table 8 (study 1) and Table 9 (study 2). In study 1, there was significant improvement of the mean VAS score for "relieved" from $51.2 \pm 19.4$ at baseline to $65.8 \pm$ 17.0 in week 8, indicating improvement of mood among the subjects. The VAS scores for other items ("feeling refreshed", "comfortable", "pleasurable", "light-hearted", and "relaxed") also increased in weeks 4 and 8.
In study 2, the VAS score for "pleasurable" was significantly higher in the singing group compared to the non-singing group. The VAS scores of the other items ("relieved", "feeling refreshed", "comfortable", "light-hearted", and "relaxed") were also higher at week 4 in the singing group compared with the non-singing group, but the differences were not significant.

\section{Discussion}

Good oral function is critical for various fundamental daily activities, both biological and social. Impairment of oral function, such as the ability to chew or swallow food, not only impacts the quality of life but can also lead to serious illness or require invasive medical interventions (such as insertion of a feeding tube). Deterioration of oral function can arise from organic or psychological causes. Psychological stress can exacerbate many diseases, while many disease processes can be better controlled by reducing stress $[25,26]$. Therefore, it is essential to maintain proper oral function and reduce psychological stress. It has been reported that music therapy is effective for pain [27] and for autism spectrum disorder [28]. In addition, it was reported that singing improves respiratory function in patients with chronic neurological conditions [29]. In this study, we investigated the efficacy of singing as a method of reducing psychological stress and improving oral function.

From middle age, there is a decline of the ability to swallow saliva and chew food. Our open-label study (study 1) showed that singing led to significant improvement of the RSST in weeks 4 and 8 , while evaluation of chewing (by the bite force test assessing the strength of the masticatory muscles) revealed an increase of muscle strength in week 8. Thus, participants in study 1 showed improvement of oral function after 8 weeks of singing 4 times per week. In our cross-over study (study 2), the singing group showed significant improvement of the secretion of saliva (unstimulated saliva test) in week 4 compared with the non-singing group. Salivary glands are supported by the muscles of the oral cavity, and singing both strengthens these muscles and promotes local blood flow, which may explain how singing promotes saliva production. Reduction of saliva production, swallowing, and chewing are risk factors for aspiration pneumonia. Therefore, the present findings suggest that singing not only improves oral function, including saliva production and chewing, but may also reduce the risk of aspiration pneumonia.

The sympathetic and parasympathetic nervous systems are interrelated and exquisitely balanced components of the autonomic nervous system, which have a considerable impact on immune function (e.g., lymphocyte activity) [30]. Granulocytes increase when stress increases and sympathetic activity is predominant for an extended period. Conversely, when stress declines and parasympathetic activity becomes predominant, the number of lymphocytes (immunocompetent cells) increases. We observed a significant increase of lymphocytes after singing, which suggests that singing may influence the autonomic 
Table 4. Swallowing and oral function in study 2 .

\begin{tabular}{|c|c|c|c|c|c|c|c|c|c|c|c|c|c|c|c|c|c|c|c|c|}
\hline \multirow[b]{3}{*}{ RSST } & \multirow[b]{3}{*}{ (times) } & \multicolumn{8}{|c|}{ Non-singing group } & \multicolumn{10}{|c|}{ Singing group } & \multirow{3}{*}{\begin{tabular}{|c}
$\begin{array}{c}\text { Analysis } \\
\text { of } \\
\text { variance }\end{array}$ \\
0.38
\end{tabular}} \\
\hline & & \multicolumn{3}{|c|}{ Baseline } & \multicolumn{3}{|c|}{ week 4} & \multicolumn{2}{|c|}{ Change } & \multicolumn{4}{|c|}{ Baseline } & \multicolumn{3}{|c|}{ week 4} & \multicolumn{3}{|c|}{ Change } & \\
\hline & & 4.2 & \pm & 1.1 & 4.2 & \pm & 1.1 & 0 & \pm & 0.6 & 3.9 & \pm & 0.9 & 4.1 & \pm & 1.1 & 0.2 & \pm & 0.9 & \\
\hline Bite force test & $(\mathrm{kN})$ & 0.056 & \pm & 0.029 & 0.061 & \pm & 0.02 & 0 & \pm & 0 & 0.1 & \pm & 0.035 & 0.063 & \pm & 0.029 & 0.004 & \pm & 0.03 & 0.824 \\
\hline $\begin{array}{l}\text { Unstimulated } \\
\text { saliva test }\end{array}$ & $(\mathrm{mL})$ & 4 & \pm & 2.8 & 3.7 & \pm & 2.1 & -0.3 & \pm & 1.4 & 3.5 & \pm & 2.3 & 4.1 & \pm & 2.2 & 0.6 & \pm & 1.3 & 0.013 \\
\hline Saxon test & (g) & 5 & \pm & 2 & 5.2 & \pm & 2.1 & 0.2 & \pm & 0.7 & 5 & \pm & 2.2 & 5.3 & \pm & 1.8 & 0.3 & \pm & 0.8 & 0.839 \\
\hline gum test & $(\mathrm{mL})$ & 17.8 & \pm & 7.4 & 17.3 & \pm & 7.6 & -0.5 & \pm & 1.5 & 18 & \pm & 7.6 & 18.9 & \pm & 7.6 & 1.3 & \pm & 3.7 & 0.115 \\
\hline
\end{tabular}

Data are shown as the mean $\pm \mathrm{SD}(\mathrm{n}=17)$.

RSST, repetitive saliva swallowing test; SD, standard deviation

Table 5. Immune function parameters in study 1

\begin{tabular}{|c|c|c|c|c|c|c|c|c|c|c|}
\hline \multirow{2}{*}{$\begin{array}{c}\text { Item } \\
\text { Immunity score }\end{array}$} & & \multicolumn{3}{|c|}{ Baseline } & \multicolumn{3}{|c|}{ week 4} & \multicolumn{3}{|c|}{ week 8} \\
\hline & & 14.2 & \pm & 1.5 & 15.4 & \pm & $1.7^{* *}$ & 15.8 & \pm & $1.9^{* *}$ \\
\hline Immunity grade & & 2.7 & \pm & 0.5 & 3.0 & \pm & $0.4^{*}$ & 3.0 & \pm & 0.6 \\
\hline T lymphocyte age & & 59.7 & \pm & 11.4 & 58.7 & \pm & 11.8 & 56.8 & \pm & 14.2 \\
\hline $\mathrm{CD} 3+\mathrm{T}$ cells & $(\%)$ & 64.8 & \pm & 9.2 & 66.5 & \pm & 8.3 & 68.5 & \pm & $8.3^{*}$ \\
\hline CD20+B cells & $(\%)$ & 15.1 & \pm & 4.8 & 16.6 & \pm & $4.9^{*}$ & 14.4 & \pm & 5.7 \\
\hline $\mathrm{CD} 4+\mathrm{T}$ cells & $(\%)$ & 45.6 & \pm & 8.2 & 46.5 & \pm & 6.1 & 47.1 & \pm & 7.4 \\
\hline CD8+T cells & $(\%)$ & 14.6 & \pm & 5.3 & 16.7 & \pm & 6.0 & 18.8 & \pm & 7.1 \\
\hline CD4+ naïve $\mathrm{T}$ cells & $(\%)$ & 33.5 & \pm & 7.0 & 40.1 & \pm & $10.6^{* *}$ & 37.9 & \pm & $10.9^{*}$ \\
\hline CD4+ memory T cells & $(\%)$ & 66.5 & \pm & 7.0 & 59.9 & \pm & $10.6^{* *}$ & 62.1 & \pm & $10.9^{*}$ \\
\hline CD8 T cell subset CD28+ & $(\%)$ & 64.2 & \pm & 18.5 & 65.2 & \pm & 16.5 & 66.5 & \pm & 20.8 \\
\hline CD56+/16- NK cells & $(\%)$ & 6.4 & \pm & 3.1 & 5.7 & \pm & 4.2 & 6.3 & \pm & 6.2 \\
\hline CD56+/16+ NK cells & $(\%)$ & 13.7 & \pm & 7.4 & 12.9 & \pm & 6.8 & 13.3 & \pm & 7.4 \\
\hline CD56-/16+ NK cells & $(\%)$ & 2.0 & \pm & 1.8 & 1.2 & \pm & 0.7 & 0.6 & \pm & $0.3^{* *}$ \\
\hline Neutrophils & $/ \mu \mathrm{L}$ & 3117.3 & \pm & 1357.4 & 2828.5 & \pm & 1435.2 & 2710.1 & \pm & 1057.2 \\
\hline Lymphocytes & $/ \mu \mathrm{L}$ & 1631.7 & \pm & 470.4 & 1576.5 & \pm & 415.1 & 1611.2 & \pm & 310.9 \\
\hline $\mathrm{T}$ cells & $/ \mu \mathrm{L}$ & 1070.9 & \pm & 401.5 & 1056.2 & \pm & 334.0 & 1106.4 & \pm & 263.4 \\
\hline B cells & $/ \mu \mathrm{L}$ & 247.9 & \pm & 261.2 & 445.6 & \pm & 98.6 & 229.9 & \pm & 88.5 \\
\hline CD4+ T cells & $/ \mu \mathrm{L}$ & 747.1 & \pm & 274.0 & 735.1 & \pm & 215.0 & 762.7 & \pm & 202.3 \\
\hline CD8+ T cells & $/ \mu \mathrm{L}$ & 238.3 & \pm & 100.2 & 257.5 & \pm & 89.4 & 293.8 & \pm & 106.6 \\
\hline $\mathrm{CD} 4+/ \mathrm{CD} 8+\mathrm{T}$ cell ratio & & 3.8 & \pm & 2.7 & 3.6 & \pm & 3.2 & 3.4 & \pm & 3.4 \\
\hline Naïve T cells & $/ \mu \mathrm{L}$ & 253.4 & \pm & 115.7 & 301.0 & \pm & $142.6^{* *}$ & 285.8 & \pm & 107.2 \\
\hline Memory T cells & $/ \mu \mathrm{L}$ & 493.7 & \pm & 175.4 & 434.1 & \pm & 123.7 & 476.8 & \pm & 172.3 \\
\hline Naïve /memory $\mathrm{T}$ cell ratio & & 0.5 & \pm & 0.2 & 0.7 & \pm & $0.3^{* *}$ & 0.7 & \pm & $0.3^{*}$ \\
\hline NK cells & $/ \mu \mathrm{L}$ & 215.6 & \pm & 124.7 & 200.1 & \pm & 107.0 & 210.6 & \pm & 117.2 \\
\hline $\mathrm{CD} 8+/ \mathrm{CD} 28+$ cells & $/ \mu \mathrm{L}$ & 144.0 & \pm & 58.8 & 161.2 & \pm & 58.1 & 192.5 & \pm & $91.9^{*}$ \\
\hline
\end{tabular}

Data are shown as the mean \pm SD $(n=13)$.

${ }^{*} \mathrm{p}<0.05,{ }^{* *} \mathrm{p}<0.01$ : Wilcoxon signed-rank test vs. Baseline.

$\mathrm{SD}$, standard deviation

Table 6. Changes of hormones and oxidative parameters in study 1

\begin{tabular}{|c|c|c|c|c|c|c|c|c|c|c|}
\hline Item & & & seli & & & reek & & & eek & \\
\hline Blood cortisol & $(\mu \mathrm{g} / \mathrm{dL})$ & 7.08 & \pm & 1.32 & 6.31 & \pm & 1.29 & 6.04 & \pm & $1.48^{*}$ \\
\hline $\begin{array}{c}\text { Blood } \\
\text { adrenaline }\end{array}$ & $(\mathrm{ng} / \mathrm{mL})$ & 0.040 & \pm & 0.020 & 0.033 & \pm & 0.016 & 0.030 & \pm & $0.021^{*}$ \\
\hline $\begin{array}{c}\text { Blood } \\
\text { noradrenaline }\end{array}$ & $(\mathrm{ng} / \mathrm{mL})$ & 0.514 & \pm & 0.282 & 0.505 & \pm & 0.247 & 0.418 & \pm & 0.142 \\
\hline $\begin{array}{l}\text { Blood lipid } \\
\text { peroxide }\end{array}$ & $(\mathrm{nmol} / \mathrm{mL})$ & 3.12 & \pm & 0.57 & 2.74 & \pm & $0.47^{* *}$ & 2.86 & \pm & 0.57 \\
\hline Urine 8-oxodG & $\begin{array}{l}\text { (ng/mg } \\
\text { creatinine) }\end{array}$ & 8.802 & \pm & 9.316 & 8.437 & \pm & 6.488 & 6.651 & \pm & 4.319 \\
\hline
\end{tabular}

Data are shown as the mean $\pm \mathrm{SD}(\mathrm{n}=13)$.

${ }^{*} \mathrm{p}<0.05,{ }^{* *} \mathrm{p}<0.01$ : Wilcoxon signed-rank test vs. Baseline.

8-OHdG, 8-hydroxy-2'-deoxyguanosine; SD, standard deviation 
Table 7. Changes of hormones and oxidative parameters in study 2

\begin{tabular}{|c|c|c|c|c|c|c|c|c|c|c|c|c|c|c|c|c|c|c|c|c|}
\hline \multirow[b]{3}{*}{ Cort } & \multirow[b]{3}{*}{$(\mu \mathrm{g} / \mathrm{dL})$} & \multicolumn{9}{|c|}{ Non-singing group } & \multicolumn{9}{|c|}{ Singing group } & \multirow{3}{*}{\begin{tabular}{|c}
$\begin{array}{c}\text { Analysis } \\
\text { of } \\
\text { variance }\end{array}$ \\
0.481 \\
\end{tabular}} \\
\hline & & \multicolumn{3}{|c|}{ Baseline } & \multicolumn{3}{|c|}{ week 4} & \multicolumn{3}{|c|}{ Change } & \multicolumn{3}{|c|}{ Baseline } & \multicolumn{3}{|c|}{ week 4} & \multicolumn{3}{|c|}{ Change } & \\
\hline & & 8.25 & \pm & 2.67 & 7.43 & \pm & 3.45 & -0.82 & \pm & 3.55 & 8.00 & \pm & 2.27 & 7.94 & \pm & 2.91 & -0.06 & \pm & 2.67 & \\
\hline $\mathrm{AD}$ & $(\mathrm{ng} / \mathrm{mL})$ & 0.021 & \pm & 0.013 & 0.021 & \pm & 0.011 & 0.000 & \pm & 0.008 & 0.023 & \pm & 2.290 & 0.022 & \pm & 0.016 & -0.001 & \pm & 0.009 & 0.903 \\
\hline NA & $(\mathrm{ng} / \mathrm{mL})$ & 0.443 & \pm & 0.146 & 0.499 & \pm & 0.168 & 0.056 & \pm & 0.108 & 0.441 & \pm & 0.130 & 0.531 & \pm & 0.201 & 0.091 & \pm & 0.132 & 0.205 \\
\hline LP & $(\mathrm{nmol} / \mathrm{mL})$ & 3.10 & \pm & 0.46 & 2.81 & \pm & 0.53 & -0.29 & \pm & 0.42 & 3.12 & \pm & 0.49 & 2.86 & \pm & 0.44 & -0.25 & \pm & 0.29 & 0.744 \\
\hline $8-\mathrm{OH}$ & (ng/mg creatinine) & 6.931 & \pm & 3.532 & 8.109 & \pm & 5.758 & 1.178 & \pm & 3.755 & 7.705 & \pm & 3.592 & 6.977 & \pm & 4.454 & -0.729 & \pm & 3.009 & 0.128 \\
\hline
\end{tabular}

Data are shown as the mean $\pm \mathrm{SD}(\mathrm{n}=17)$.

Cort, blood cortisol; AD, blood adrenaline; NA, blood noradrenaline; LP, blood lipid peroxide; 8-OH, urine 8-hydroxy-2'-deoxyguanosine;

$\mathrm{SD}$, standard deviation.

Table 8. Results of the questionnaire in study 1 (VAS)

\begin{tabular}{|c|c|c|c|c|c|c|c|c|c|}
\hline \multirow[b]{2}{*}{ Refreshed } & \multicolumn{3}{|c|}{ Baseline } & \multicolumn{3}{|c|}{ week 4} & \multicolumn{3}{|c|}{ week 8} \\
\hline & 53.1 & \pm & 20.3 & 55.1 & \pm & 21.1 & 61.9 & \pm & 16.0 \\
\hline Comfortable & 53.2 & \pm & 16.5 & 54.3 & \pm & 19.5 & 61.0 & \pm & 14.6 \\
\hline Pleasurable & 51.5 & \pm & 22.6 & 58.4 & \pm & 21.1 & 59.0 & \pm & 20.6 \\
\hline Light hearted & 49.8 & \pm & 21.7 & 57.5 & \pm & 22.8 & 57.5 & \pm & 20.0 \\
\hline Relieved & 51.2 & \pm & 19.4 & 53.4 & \pm & 18.4 & 65.8 & \pm & $17.0^{*}$ \\
\hline Relaxed & 53.5 & \pm & 20.7 & 59.8 & \pm & 21.5 & 64.3 & \pm & 16.6 \\
\hline
\end{tabular}

Data are shown as the mean \pm SD $(n=13)$.

${ }^{*} \mathrm{p}<0.05, * * \mathrm{p}<0.01$ : Wilcoxon signed-rank test vs. Baseline.

VAS score 0: Not At all, VAS score 100: Extremely

SD, standard deviation; VAS, Visual Analog Scale

The subjects marked the position that fitted their current state on a $100 \mathrm{~mm}$ line

Table 9. Results of the questionnaire in study 2 (VAS)

\begin{tabular}{|c|c|c|c|c|c|c|c|c|c|c|c|c|c|c|c|c|c|c|c|}
\hline \multirow[b]{3}{*}{ Refreshed } & \multicolumn{9}{|c|}{ Non-singing group } & \multicolumn{9}{|c|}{ Singing group } & \multirow{3}{*}{$\begin{array}{c}\text { Analysis of variance } \\
0.422\end{array}$} \\
\hline & \multicolumn{3}{|c|}{ Baseline } & \multicolumn{3}{|c|}{ week 4} & \multicolumn{3}{|c|}{ Change } & \multicolumn{3}{|c|}{ Baseline } & \multicolumn{3}{|c|}{ week 4} & \multicolumn{3}{|c|}{ Change } & \\
\hline & 61.9 & \pm & 19.2 & 63.9 & \pm & 18.7 & 2.0 & \pm & 22.1 & 55.8 & \pm & 20.8 & 64.7 & \pm & 12.9 & 8.9 & \pm & 21.4 & \\
\hline Comfortable & 59.4 & \pm & 16.5 & 63.0 & \pm & 20.2 & 3.6 & \pm & 19.8 & 56.4 & \pm & 21.7 & 63.9 & \pm & 14.8 & 7.5 & \pm & 25.3 & 0.623 \\
\hline Pleasurable & 66.0 & \pm & 18.1 & 56.7 & \pm & 18.8 & -9.2 & \pm & 17.8 & 56.6 & \pm & 19.5 & 65.6 & \pm & 14.6 & 9.0 & \pm & 21.0 & 0.035 \\
\hline Light hearted & 53.1 & \pm & 22.0 & 64.0 & \pm & 20.9 & 10.9 & \pm & 28.9 & 55.0 & \pm & 24.2 & 62.9 & \pm & 19.4 & 7.9 & \pm & 30.8 & 0.706 \\
\hline Relieved & 62.1 & \pm & 20.6 & 61.0 & \pm & 18.0 & -1.1 & \pm & 22.0 & 56.5 & \pm & 19.6 & 66.2 & \pm & 19.9 & 9.8 & \pm & 21.3 & 0.239 \\
\hline Relaxed & 61.4 & \pm & 20.7 & 61.4 & \pm & 19.7 & 0.0 & \pm & 22.1 & 56.5 & \pm & 23.0 & 67.0 & \pm & 18.2 & 10.4 & \pm & 24.0 & 0.293 \\
\hline
\end{tabular}

Data are shown as the mean \pm SD $(n=13)$.

VAS score 0: Not At all, VAS score 100: Extremely

balance. In week 8 of study 1, there was a significant decrease of adrenaline and cortisol levels (which are elevated by stress), and the questionnaire results suggested that stress was reduced among the participants. In study 2, the questionnaire results showed improvement in the singing group compared with the non-singing group, although blood levels of adrenaline and cortisol did not differ between the two groups. These results combined with immunological data (study 1) suggest that singing reduces stress and improves immune function.

Oxidative stress is influenced by mental health and environmental factors, and this type of stress may play a role in the onset of various diseases, including type II diabetes and cancer [31]. Cell membranes are composed of unsaturated fatty acids, and lipid peroxides can easily damage these molecules, potentially leading to disease [32]. Moreover, In addition, 8-OHdG has various pathologic effects and its urine level is measured as an indicator of oxidative stress [33]. In study 1, we observed a significant decrease of lipid peroxide in week 4 and urine levels of 8-OHdG also decreased over the 8 -week study period. In study 2 , the urine $8-\mathrm{OHdG}$ level decreased in the singing group while increasing in the non-singing group, although there was no significant difference between the two groups. These findings suggest that singing may have the potential to prevent various diseases by reducing oxidative stress. In this context, it was previously demonstrated that production of reactive oxygen species in rats subjected to immobilization stress was decreased by eating behavior, including chewing $[34,35]$.
Because this small-scale study showed that daily singing improves psychological stress and mental health, further investigation is warranted to evaluate the effect of singing in a larger study.

\section{Conclusions}

In our 2 studies, singing on a regular basis for 1-2 months increased secretion of saliva, as well as leading to improvement of chewing and swallowing. Singing therapy was also associated with reduction of psychological stress, and may potentially prevent/delay various diseases by reducing oxidative stress and improving immune function.

\section{Author Contributions}

KS conceived the study, participated in the study design, performed data collection, and drafted the manuscript. KR, YT, RN, and SF performed statistical analysis.

SE participated in the study design and performed data collection. KT participated in the study design. IS reviewed the study. All authors read and approved the final manuscript.

\section{Acknowledgments}

Editorial support in the form of copyediting and manuscript formatting was provided by Cactus Communications and funded by Daiichikosho Co., Ltd. 


\section{Funding} Co., Ltd.

This study was conducted with funding received from Daiichikosho

\section{Competing Interests}

The authors declare that they have no competing interests and these data have not been published or used before in any manner in a journal article.

\section{References}

1. Yuki M, Maddux WW, Masuda T (2007) Are the windows to the soul the same in the East and West? Cultural differences in using the eyes and mouth as cues to recognize emotions in Japan and the United States. J ExperimentSoc Psychol 43: 303-311.

2. Kaye EK, Valencia A, Baba N, Spiro A 3rd, Dietrich T, et al. (2010) Tooth loss and periodontal disease predict poor cognitive function in older men. $J$ Am Geriatr Soc 58: 713-718.

3. Oomura Y, Sasaki K, Li AJ (1993) Memory facilitation educed by food intake. Physiol Behavi 54: 493-498.

4. Soares RV, Lin T, Siqueira CC, Bruno LS, Li X, et al. (2004) Salivary micelles: identification of complexes containing MG2, sIgA, lactoferrin, amylase, glycosylated proline-rich protein and lysozyme. Arch Oral Biol 49, 337-343.

5. Tenovuo J, Lehtonen OP, Aaltonen AS, Vilja P, Tuohimaa P (1986) Antimicrobial factors in whole saliva of human infants. Infect Immun 51: 49-53. [Crossref]

6. White MR, Helmerhorst EJ, Ligtenberg A, Karpel M, Tecle T, et al. (2009) Multiple components contribute to ability of saliva to inhibit influenza viruses. Oral Microbiol Immunol 24: 18-24.

7. Battino M, Ferreiro MS, Gallardo I, Newman HN, Bullon P (2002) The antioxidant capacity of saliva. J Clin Periodontol 29: 189-194. [Crossref]

8. Kurita N, Horie S, Yamazaki S, Otoshi K, Otani K, et al. (2014) Low testosterone levels, depressive symptoms, and falls in older men: a cross-sectional study. $J$ the $\mathrm{Am}$ Med Directors Assoc 15: 30-35.

9. Ryo K, Ito A, Takatori R, Tai Y, Arikawa K, et al. (2011) Effects of coenzyme Q10 on salivary secretion. Clin Biochem 44: 669-674. [Crossref]

10. Ryo, K, Takahashi A, Tamaki Y, Ohnishi-Kameyama M, Inoue H, et al. (2014) Therapeutic effects of isoflavones on impaired salivary secretion. $J$ Clin Bioch Nutr 55: $168-173$.

11. Yamada T, Ryo K, Tai Y, Tamaki Y, Inoue H, et al. (2010) Evaluation of therapeutic effects of astaxanthin on impairments in salivary secretion. J Clin Biochem Nutri 47: $130-137$.

12. Challacombe SJ, Percival RS, Marsh PD (1995) Age-related changes in immunoglobulin isotypes in whole and parotid saliva and serum in healthy individuals. Oral Microbiol Immunol 10: 202-207.

13. Miletic ID, Schiffman SS, Miletic VD, Sattely-Miller EA (1996) Salivary IgA secretion rate in young and elderly persons. Physiol Behav 60: 243-248.

14. Matsuse T, Oka T, Kida K, Fukuchi Y (1996) Importance of diffuse aspiration bronchiolitis caused by chronic occult aspiration in the elderly. Chest, 110: 1289-1293.

15. Holt-Lunstad J, Smith TB, Layton JB (2010) Social relationships and mortality risk: a meta-analytic review. PLoS Med 7: e1000316. [Crossref]

16. Holt-Lunstad J, Smith TB, Baker M, Harris T, Stephenson D (2015) Loneliness and social isolation as risk factors for mortality: a meta-analytic review. Perspect Psychol Sci 10: 227-237. [Crossref]

17. Cao L, Choi EY, Liu X, Martin A, Wang C, et al. (2011) White to brown fat phenotypic switch induced by genetic and environmental activation of a hypothalamic-adipocyte axis. Cell Met 14: 324-338.
18. Ramirez S, Liu X, MacDonald CJ, Moffa A, Zhou J, et al. (2015) Activating positive memory engrams suppresses depression-like behavior. Nature 522: 335-339.

19. Shirai K, Iso H, Ohira T, Ikeda A, Noda H, et al. (2009) Perceived level of life enjoyment and risks of cardiovascular disease incidence and mortality: the Japan public health center-based study. Circulation 120: 956-963.

20. Sreebny LM (2000) Saliva in health and disease: an appraisal and update. Int Dent J 50: 140-161. [Crossref]

21. Wiswede D, Münte TF, Krämer UM, Rüsseler J (2009) Embodied emotion modulates neural signature of performance monitoring. PLoS One 4: e5754.

22. Sakano K, Ryo K, Tamaki Y, Nakayama R, Hasaka A, et al. (2014) Possible benefits of singing to the mental and physical condition of the elderly. BioPsychoSocial Medicine 21: $8-11$.

23. Utsuyama M, Kikuchi Y, Kitagawa M, Hirokawa K (2009) Age-related changes in subpopulations of peripheral blood lymphocytes in healthy Japanese population. In Handbook on Immunosenescence: Basic Understanding and Clinical Applications. Fulop, T, Franceschi, C, Hirokawa, K, Pawelec, G. (eds) Berlin/Heidelberg: Springer Science+Business Media, 204-218.

24. Hirokawa K, Utsuyama M, Kikukchi Y, Kitagawa M (2009) Assessment of agerelated decline of immunological function and possible methods for immunological restoration in elderly. In Handbook on Immunosenescence: Basic Understanding and Clinical Applications, Fulop, T, Franceschi, C, Hirokawa, K, Pawelec, G. (eds) Berlin/ Heidelberg: Springer Science+Business Media, 1548-1569.

25. Iso H, Date C, Yamamoto A, Toyoshima H, Tanabe N, et al. (2002) Perceived menta stress and mortality from cardiovascular disease among Japanese men and women: the Japan Collaborative Cohort Study for Evaluation of Cancer Risk Sponsored by Monbusho (JACC Study). Circulation 106: 1229-1236.

26. Veenhoven R (2008) Healthy happiness: effects of happiness on physical health and the consequences for preventive health care. J Happiness Stud 9: 449-469.

27. Lee JH (2016) The Effects of Music on Pain: A Meta-Analysis. J Music Ther 53: 430477. [Crossref]

28. Geretsegger M, Holck U, Carpente JA, Elefant C, Kim J, et al. (2015) Common characteristics of improvisational approaches in music therapy for children with autism spectrum disorder: developing treatment guidelines. J Music Ther 52: 258-81.

29. Ang K, Maddocks M, Xu H, Higginson IJ (2017) The effectiveness of singing or playing a wind instrument in improving respiratory function in patients with long-term neurological conditions: A systematic review. J Music Ther 54: 108-131.

30. Nakai A, Hayano Y, Furuta F, Noda M, Suzuki K (2014) Control of lymphocyte egress from lymph nodes through 32 -adrenergic receptors. Journal of Experimental Medicine, $211,2583-2598$.

31. Cencioni C, Spallotta F, Martelli F, Valente S, Mai A, et al. (2013) Oxidative stress and epigenetic regulation in ageing and age-related diseases. Int J Mol Sci 14: 1764317663.

32. Finkel T, Holbrook NJ (2000) Oxidants, oxidative stress and the biology of ageing. Nature 408: 239-247. [Crossref]

33. Mei N, Tamae K, Kunugita N, Hirano T, Kasai H (2001) Analysis of 8-hydroxydeoxyguanosine as a marker of oxidative stress. Foods \& Food Ingred $J$ Japan 194: 10-16.

34. Hori N, Lee MC, Sasaguri K, Ishii H, Kamei M, et al. (2005) Suppression of stressinduced nNOS expression in the rat hypothalamus by biting. J Dent Res 84: 624-628. [Crossref]

35. Miyake S, Sasaguri K, Hori N, Shoji H, Yoshino F, et al. (2005) Biting reduces acute stress-induced oxidative stress in the rat hypothalamus. Redox Report, 10, 19-24.

Copyright: $\odot 2018$ Sakano K. This is an open-access article distributed under the terms of the Creative Commons Attribution License, which permits unrestricted use, distribution, and reproduction in any medium, provided the original author and source are credited. 